\title{
A safety evaluation of high-speed trains by investigating the effects of mine blasting
}

\author{
H. K. Kim, S. H. Lee, J. W. Lee \& C. Y. Choi \\ High-Speed Railroad System Research Center, \\ Korea Railroad Research Institute (KRRI), Korea
}

\begin{abstract}
Recently, the Honam high-speed railroad line was constructed in the southern part of Korea. This line is for a next generation high-speed train (HST) named HEMU430X. But there is a limestone mine near the Honam HSR line and this mine will proceed to dig a passageway under the Honam line. In this case, the safety of the railroad system and the stability of the mine are crucial problems on both sides. By measuring the mine blasting vibration and calculating the regression equation, the effect of mine blasting to the trains running is investigated quantitatively. By applying $0.5 \mathrm{kine}(\mathrm{cm} / \mathrm{sec})$ as a management specification, the safe region of the mine blasting is defined. Train induced vibration is also investigated to evaluate the stability of mine. By comparing the results of vibration propagation properties, the location and shape of a passageway is determined in this study.
\end{abstract}

Keywords: high-speed train, mine blasting, vibration, passageway, safety evaluation.

\section{Introduction}

Recently, various transportation systems have been developed for business, recreation and so on. The high speed railroad (HSR) system is one of the safest, the fastest and the most representative means of transportation in Korea. HSR makes Korea appear to be more like a city because of its HSR links. The Honam high-speed railroad line (Osong-Mokpo) is a main line along with the Gyeongbu line in Korea. It will be $230.99 \mathrm{~km}$ long and is in the process of being constructed, scheduled to open in 2015.

On an HSR line, it is prohibited to create rapid variations in the track and there are many limitations in the horizontal and vertical geometry of it. After fixing the 
line, there might be some problems such as vibration, noise etc., which may affect other structures. Alternatives to the line are not easy to change in this case. Important structures, buildings, vibrations and noises should be considered in the design stage to avoid these problems. On the other hand, the construction and mining of minerals close to the railway line are also a big issue because they can cause damage to the railway line.

There is a limestone mine near the Honam HSR line. Mine blasting continues towards the line and furthermore it will penetrate under the line. It is crucial to secure the safety of the high speed train and infrastructures as well as mining stability.

In this study, the evaluation of the safety of HSR, a suggestion for applying blasting patterns to protect HSR and the determination of a safe region of the passageway are executed by analyzing the effects of mine blasting and HSR vibration.

\section{Status of the site}

\subsection{General information of a mine}

Geologically this area consists of limestone, granitic gneiss, schist and quartzite. Limestone mining is conducted underground by a room and pillar method. Figures 1 and 2 show a plan view and a vertical section view by geological site investigation, geological mapping and the status of the HSR line.

Limestone mine blasting is separated at two stages; digging the cut and widening the cut. The digging section is $9 \mathrm{~m}$ wide and $6 \mathrm{~m}$ high. The widening section is $18 \mathrm{~m}$ wide and $6 \mathrm{~m}$ high. In blasting works, the maximum charge per delay is about $21 \mathrm{~kg}$ and blasting is conducted at maximum charge with 6 holes in the center cut.

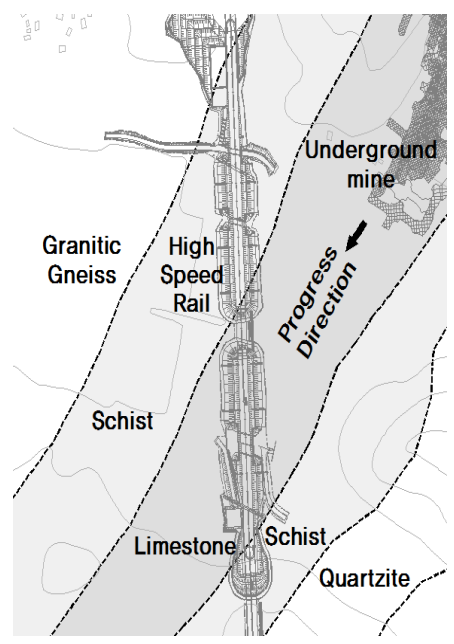

Figure 1: A plan view of the site. 


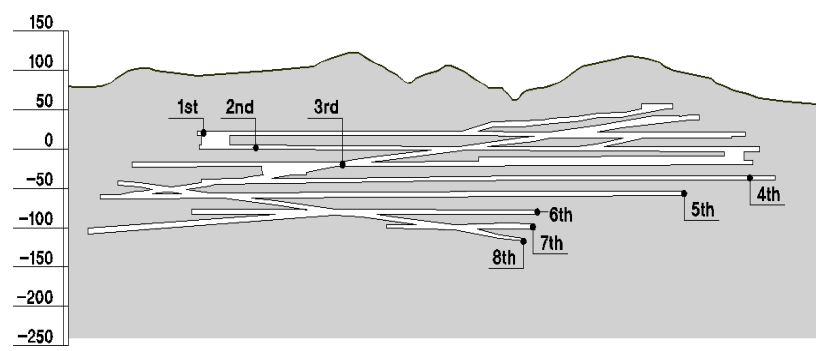

Figure 2: A section view of the underground mining.

\subsection{Honam HSR line}

The major structures in the HSR line are the bridge, the embankment and the tunnel. In particular, the bridge, with a pile foundation, and the embankment are constructed on the limestone mine. A section view is shown in Figure 3.

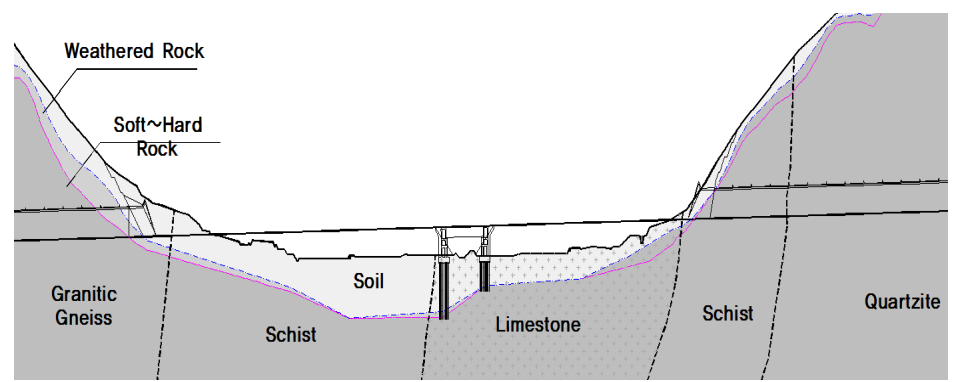

Figure 3: A section view of the high speed line with geological information.

\subsection{Wave propagation characteristics in the ground}

Underground mining is making progress in this area and mine pits are very complicated. So, the wave propagation characteristics are apparently divided into two types. One is wave propagation through the mine and the other is wave propagation into intact rock mass. These characteristics are reflected in this study to analyze the effects of blasting vibrations.
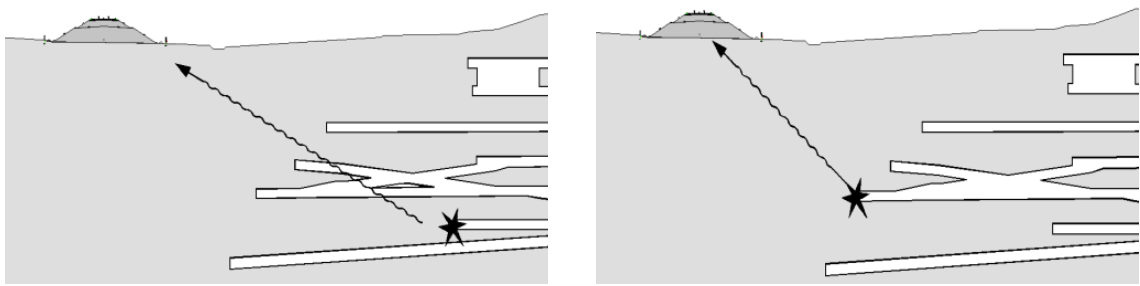

(a) Wave propagation through mine (b) Wave propagation into intact rock mass

Figure 4: Propagation of ground vibrations. 


\section{Site investigation and evaluation of mine blasting vibration}

\subsection{Site investigation}

Geophysical surveys, soil-boring investigation and laboratory tests are executed to evaluate the stability of the ground and the HSR line. These tests help to determine soil parameters and ground conditions. Figure 5 shows the geologically weak regions. This area has 19 weak regions. Geologically weak regions should be avoided for constructing a passageway.

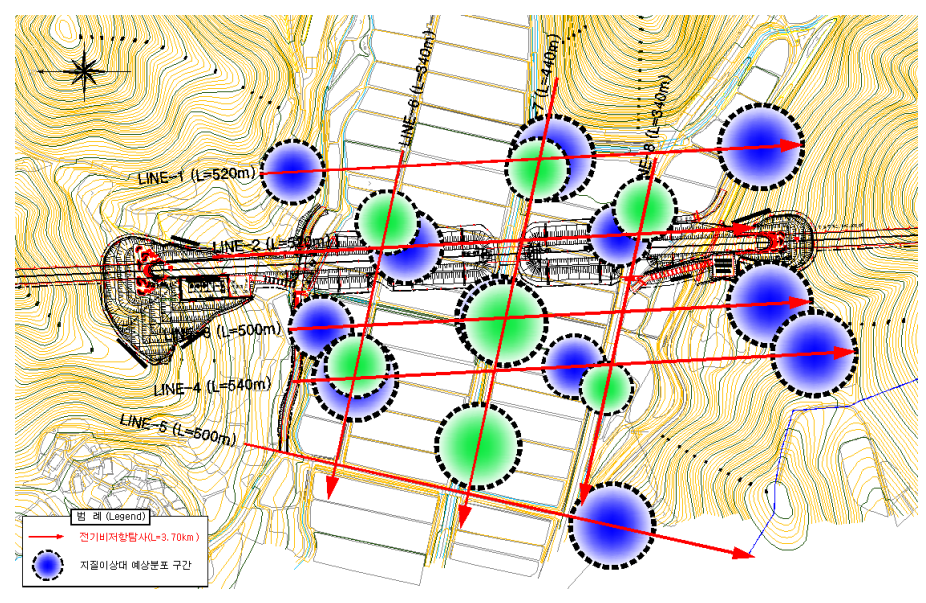

Figure 5: Geological weak regions by Electric Resistivity Survey (ERS).

\subsection{Evaluation of mine blasting vibration}

(1) Measurement of mine blasting

Mine blasting vibration is measured 10 times. Blasting for the $1^{\text {st }}-t^{\text {th }}$ time causes vibrations through the mine pits and the intact rock mass, however, blasting for the $8^{\text {th }}-10^{\text {th }}$ time creates vibrations that only travel through the intact rock mass area. Proper points are selected as the measurement point and 15-19 sensor systems are constructed for each measurement. The data acquisition rates of the sensor systems range from $521 \mathrm{~Hz}$ to $1024 \mathrm{~Hz}$. A plan view of the measurement points is shown in Figures 6 and 7 for each case of blasting.

(2) Calculation of wave propagation equations

Using Peak Particle Velocity (PPV) from measurements, the maximum charge per delay and distance between measuring points, wave propagation equations are calculated by a simple regression analysis. As previously mentioned, wave propagation equations are calculated in 2 ways for applying an analysis. Figure 8 shows the equation used to evaluate vibration into intact rock mass, adjacent to the railway line. Figure 9 shows the equation used to estimate vibration through the mine. 


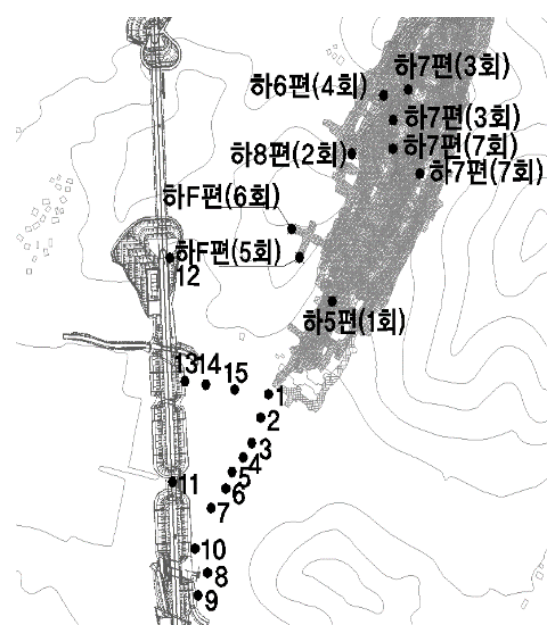

Figure 6: Blasting and measuring points ( $1^{\text {st }}-7$ th blasting).

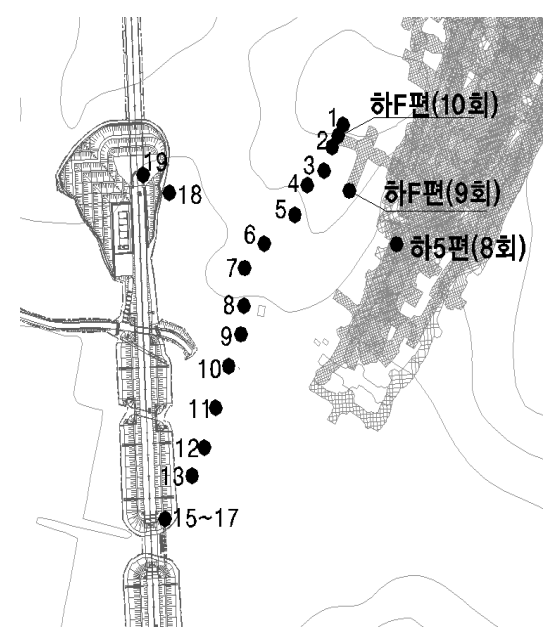

Figure 7: Blasting and measuring points ( $8^{\text {th }}-10$ th blasting).

Table 1: Blasting wave propagation equation.

\begin{tabular}{|c|c|}
\hline Category & Wave propagation equation \\
\hline Case-1 & $\mathrm{V}_{95 \%}=1554.98 \times \mathrm{SD}^{-1.972}$ \\
\hline Case-2 & $\mathrm{V}_{95 \%}=29238.35 \times \mathrm{SD}^{-2.766}$ \\
\hline
\end{tabular}




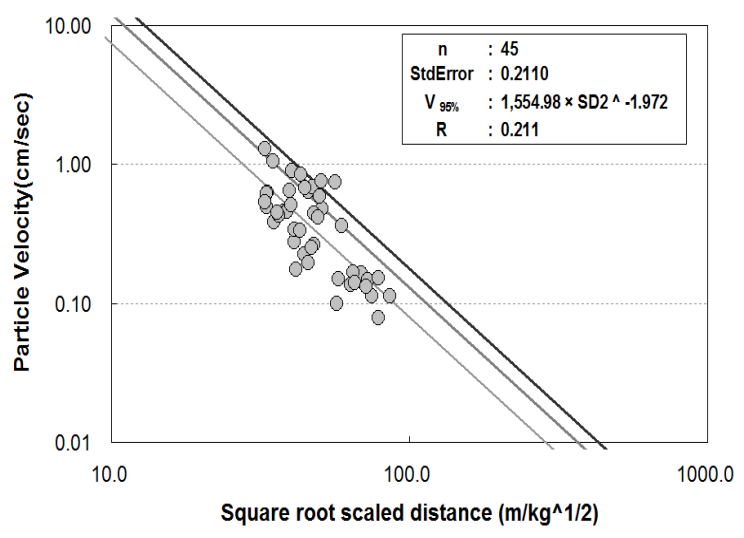

Figure 8: Wave propagation equation into intact rock mass.

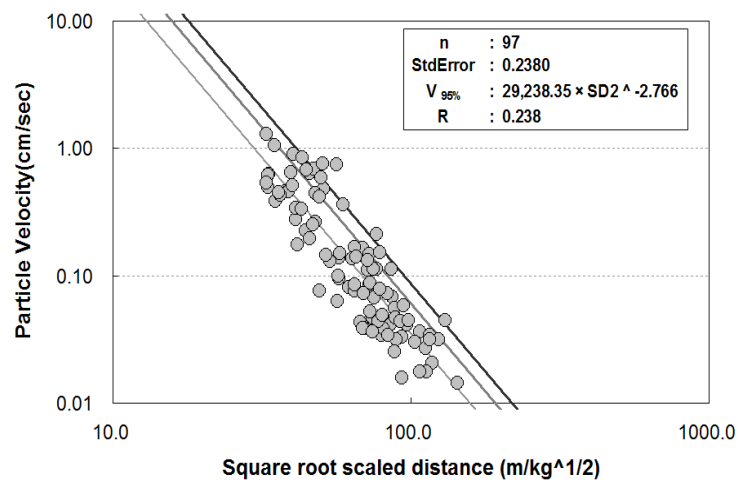

Figure 9: Wave propagation equation through mine.

\section{Vibration management specification and safety analysis}

\subsection{Vibration management specification}

Korean vibration specifications provided by organisations such as The Ministry of Land, Infrastructures and Transport [1, 2], and foreign vibration specifications such as those of USBM [3], The Japan Explosives Industry Association [4], and Din 4150 [5] are examined to set up a management specification of ground vibration. The dominant frequencies from the measurement data are calculated from $10 \mathrm{~Hz}$. Based on DIN4150, the specification can be selected between $0.3-0.8 \mathrm{kine}$ for $10-50 \mathrm{~Hz}$ in vibration sensitive structures. In this study, $0.5 \mathrm{kine}$ is selected as the specification to manage vibration on the roadbed surface. This value is the same as that of the Japanese specification used to define the starting value of vibration damages in structures. A safety analysis is executed based on this value. 


\subsection{Safety analysis of HSR line by mine blasting}

Ground vibration at any point can be predicted by using the wave propagation equation. The influence-ranges of ground vibration are set up for a management specification of $0.5 \mathrm{kine}$ at the roadbed surface. Currently, the charge per delay $(14.0 \mathrm{~kg})$ being used needs $243 \mathrm{~m}$ as a minimum safe distance. However, the influence range is easily reduced by controlling the charge per delay. The safety of the HSR line is secured to control the mine blasting patterns (Figure 10).

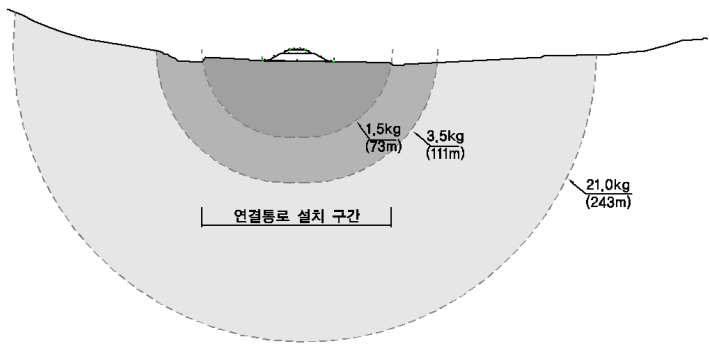

Figure 10: Vibration influence range of charge per delay (kg/delay) for $0.5 \mathrm{kine}$.

Using the above condition, mine blasting patterns are suggested with mining works space (Table 2, Figure 11).

Table 2: Charge per delay for the distance from the roadbed in railway line.

\begin{tabular}{|c|c|c|c|c|c|}
\hline Charge/delay & $<1.5 \mathrm{~kg}$ & $1.5 \mathrm{~kg}$ & $3.5 \mathrm{~kg}$ & $7.0 \mathrm{~kg}$ & $14.0 \mathrm{~kg}$ \\
\hline Interval distance & $<73 \mathrm{~m}$ & $73 \mathrm{~m}-111 \mathrm{~m}$ & $111 \mathrm{~m}-141 \mathrm{~m}$ & $141 \mathrm{~m}-199 \mathrm{~m}$ & $199 \mathrm{~m}-243 \mathrm{~m}$ \\
\hline $\begin{array}{c}\text { Propagation } \\
\text { equation }\end{array}$ & \multicolumn{2}{|c|}{ Case-1 } & \multicolumn{3}{c|}{ Case-2 } \\
\hline
\end{tabular}

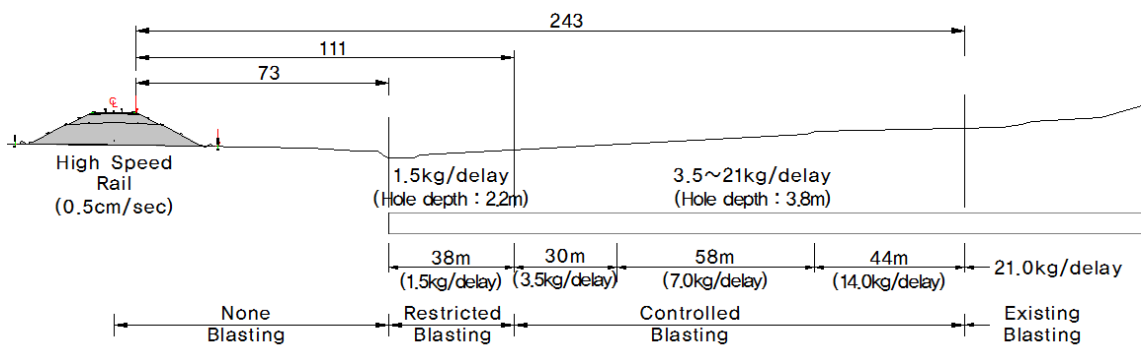

Figure 11: A method of mine blasting (charge per delay) to secure management specification of $0.5 \mathrm{kine}$. 


\subsection{Evaluation of a passageway by vibration of HST}

The design train is a KTX-II that has a maximum speed of $350 \mathrm{~km} / \mathrm{h}$ and its maximum axial load is $250 \mathrm{kN}$. This train is composed of 10 cars. The vibrations produced from this train operation vibrate into the ground and its effect upon the passageway is evaluated. The examined passageway is located beneath $130 \mathrm{~m}$ from ground level and its size is $10 \mathrm{~m} \times 5 \mathrm{~m}$.

The vibration is $0.032 \mathrm{kine}$ in the embankment area and $0.029 \mathrm{kine}$ near the bridge area. It is judged that the vibration created from the operation of the train is too small to threaten the stability of a passageway (Figures 12 and 13).
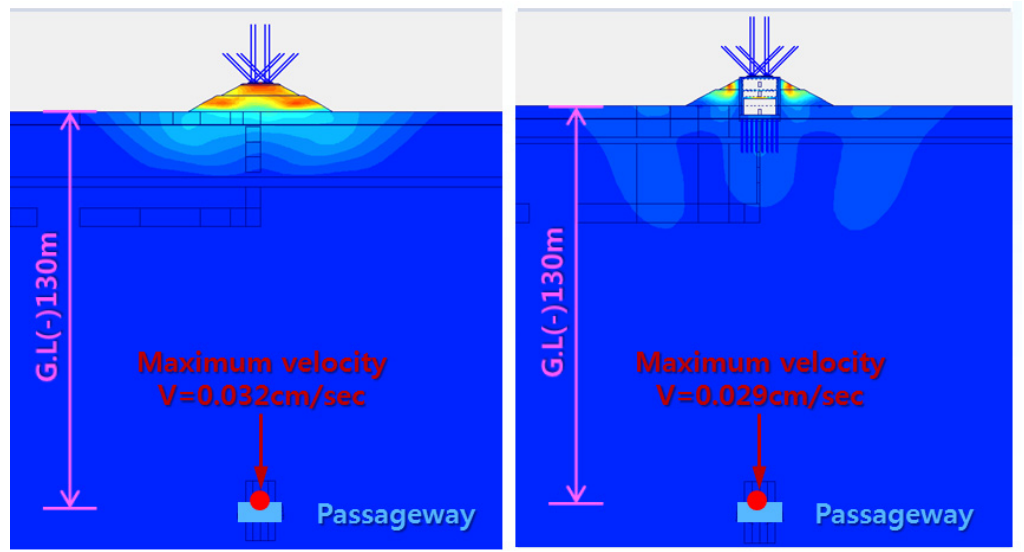

Figure 12: Maximum velocity by train vibration.

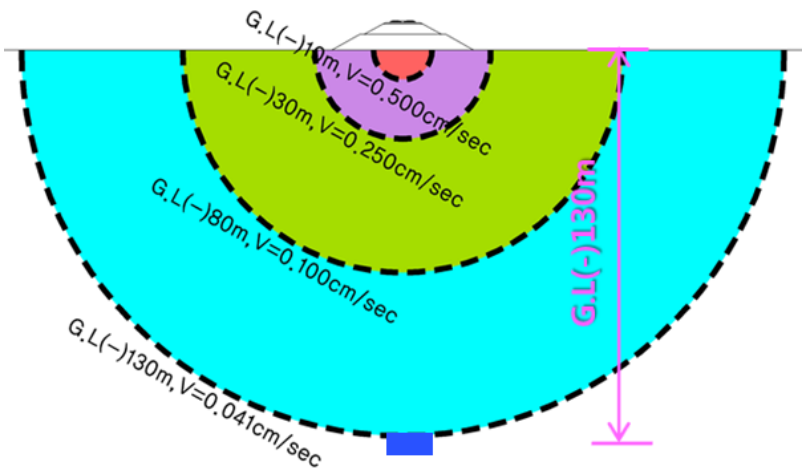

Passageway

Figure 13: Influence range of train vibration. 


\subsection{Evaluation of location of a passageway by ERS}

Generally, the examined area used to construct a passageway has high resistivity value and this means that the condition of the rock mass is very good. However, because there are geological weak regions that have a high angle (Figure 14), a passageway should be installed beneath the weak regions.

The degree of the rock mass is evaluated along a passageway. Based on the results of ERS, the major degree of the rock mass belongs to I-II. It is confirmed that the degree of rock mass in the deep area is better than the shallow area. A passageway, which is located in GL (-) 130m-140m, is the best choice to avoid rock mass area that has a III degree. In the aspect of long-term stability, it is evident that there is a need to set up $130 \mathrm{~m}$ beneath ground level.

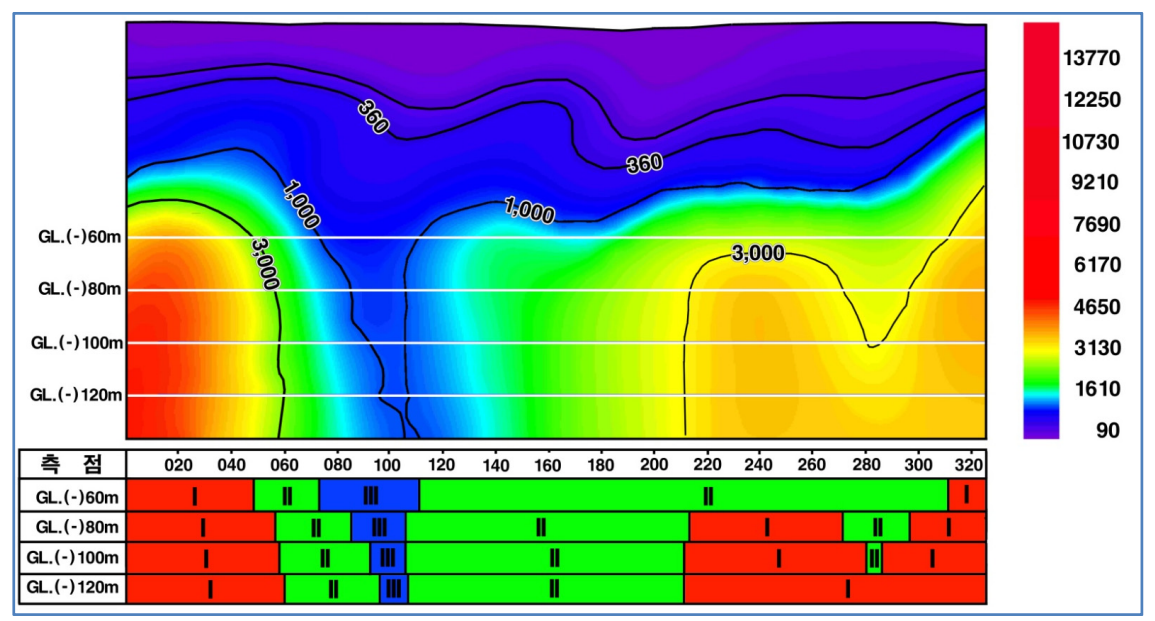

Figure 14: Distribution of degree of rock mass.

\subsection{Key block analysis of a passageway}

A key block analysis is executed using the information from the surface of discontinuity. The unit weight is $2.65 \mathrm{t} / \mathrm{m} 3$ for II degree and $2.50 \mathrm{t} / \mathrm{m}^{3}$ for III degree. The factor of safety (FOS) 1.5 is not satisfied before the installation of countermeasures. FOS 1.5 can be secured after rock bolting and shotcrete spraying. The shape of the passageway reviewed in this paper is rectangular.

\section{Conclusions}

The safety of the train is the most important aspect to protect passengers as well as freight. So it is recommended that bad external conditions are reduced. In this study, a stability analysis by mine blasting close to the Honam HSR line is examined. And the stability of a passageway is also determined by analysis of train vibration. The conclusions are as follows: 
1) Mine blasting has little effect on the safety of the Honam HSR line by applying the wave propagation equation from the measured data.

2) Train vibration into the ground is very minimal. The adjacent area of a passageway, GL (-) 130m is not affected by train vibration.

3) The optimum location of a passageway is GL (-) $130 \mathrm{~m}-140 \mathrm{~m}$ by ESR.

4) Looking at the results of the key block analysis, the FOS is protected by constructing countermeasures, such as rock bolts and shotcrete.

\section{References}

[1] Ministry of Land, Infrastructures and Transport in Korea, Design and construction guidelines for road construction open-air blast, 2006 in Korean.

[2] Ministry of Land, Infrastructures and Transport in Korea, Design criteria for railroad (road bed), 2011 in Korean.

[3] Siskind, D. E., Stagg, M. S., Kopp, J. W. and Dowding, C. H. Structure response and damage produced by ground vibration from surface mine blasting, (Report of Investigations 8507.) Washington, DC: US Bureau of Mines, pp. 74, 1980.

[4] Japan Explosives Industry Association, These explosions and those explosions, 2002 in Japanese.

[5] DIN 4150-part 3, Structural Vibration in Buildings: Effects on Structure, $1970,1986$. 